\title{
PENGARUH MOTIVASI DAN GAYA KEPEMIMPINAN TERHADAP PRODUKTIVITAS KARYAWAN PADA PT CAHAYA BERLIAN
}

\section{THE INFLUENCE OF MOTIVATION AND LEADERSHIP STYLE ON EMPLOYEE PRODUCTIVITY IN PT CAHAYA BERLIAN}

\author{
Yossi Hendriati \\ Sekolah Tinggi Ilmu Ekonomi Galileo, Batam \\ kampusgalileobatam@yahoo.co.id
}

\begin{abstract}
Low labor productivity of employees in an organization or company is a symptom or problem that can cause the company is less stable because it can cause the unfulfillment of achievement of corporate goals. This study aims to analyze the influence of motivation and leadership style on employee productivity in PT. Cahaya Berlian. The population in this research is PT Cahaya Berlian employees and the sample used is representative of the population with the number of 100 respondents by using nonprobability sampling technique in data collection. The results showed that the motivation and leadership style partially has significant effect on the performance of employees of PT. Cahaya Berlian.
\end{abstract}

Key words: motivation, leadership style, employee productivity.

\begin{abstract}
ABSTRAK
Rendahnya produktivitas kerja dari karyawan dalam suatu organisasi atau perusahaan merupakan gejala atau masalah yang dapat menyebabkan perusahaan tersebut kurang stabil karena dapat menimbulkan ketidakmaksilan pencapaian tujuan perusahaan. Penelitian ini bertujuan untuk menganalisa pengaruh motivasi dan gaya kepemimpinan terhadap produktivitas karyawan pada pt cahaya berlian. Populasi dalam penelitian ini adalah karyawan PT Cahaya Berlian dan sampel yang digunakan adalah perwakilan dari populasi dengan jumlah 100 responden dengan menggunakan teknik nonprobability sampling dalam pengumpulan data. Hasil penelitian menunjukkan bahwa motivasi dan gaya kepemimpinan secara parsial berpengaruh signifikan terhadap kinerja karyawan PT. Cahaya Berlian.
\end{abstract}

Kata Kunci : Motivasi, Gaya Kepemimpinan, Produktivitas karyawan

\section{PENDAHULUAN}

Motivasi berasal dari bahasa latin movere yang berarti dorongan atau daya penggerak. Setiap orang dalam suatu aktivitas berbeda-beda satu dengan yang lain tergantung pada kemampuan, kemauan, keinginan, harapan, kebutuhan, tujuan, sasaran, imbalan atau motif dan dorongan. Dorongan dalam diri seseorang menyebabkan mengapa ia berusaha mencapai tujuan yang direncanakan baik secara sadar atau tidak sadar 
Menurut Hersey dan Blanchard dalam Hasibuan dan Arifin (2005) manusia berbeda satu dengan yang lain, tidak hanya dalam kemampuan melakukan sesuatu tetapi juga berbeda dalam kemauan untuk melakukan sesuatu dan kemauan atau dorongan untuk melakukan sesuatu itu disebut motivasi.

Motivasi yang diberikan oleh pimpinan perusahaan terhadap karyawan akan dapat mempengaruhi produktivitas karyawan, dikarenakan motivasi yang diterima merupakan imbalan jasa atas prestasi yang telah didapatkan oleh karyawan, dikarenakan adanya imbalan jasa tersebut, maka karyawan akan semakin meningkatkan produktivitas kerja mereka

Begitu juga dengan gaya kepemimpinan, gaya kepemimpinan juga akan mempengaruhi produktivitas karyawan.

Kepemimpinan berkembang sesuai situasi dan keperluan. Hanya pemimpin yang mengetahui situasi dan keperluan organisasilah yang dapat menjadi pemimpin yang efektif.

Gaya kepemimpinan yang efektif itu berbeda-beda sesuai dengan kematangan atasan. Kematangan atau kedewasaan bukan dalam arti usia atau stabilitas emosional, melainkan; (a) keinginan untuk berprestasi, (b) kesediaan untuk menerima tanggungjawab, (c) kemampuan serta pengalaman yang berhubungan dengan tugas, tujuan dan pengetahuan pengikut merupakan variabel-variabel penting dalam menentukan gaya kepemimpinan yang efektif (Hasibuan dan Arifin 2005) Dinamika manusia yang kemudian menampakkan diri pada dinamika organisasi dan dinamika masyarakat sebagai keseluruhan merupakan faktor pendorong bagi berbagai jenis kemajuan yang dicapai manusia. Dorongan untuk maju timbul karena hasrat dan keinginan manusia untuk meningkatkan kemampuannya untuk memuaskan berbagai jenis kebutuhannya yang semakin lama semakin kompleks Berhubungan dengan peningkatan kebutuhan, maka semakin tinggi hasrat manusia untuk masuk berbagai jenis organisasi, maka semakin berkembang persepsi yang berkisar pada pandangan bahwa kehidupan organisasional perlu dijamin adanya keseimbangan antara hak dan kewajiban (Sari 2004). Dalam hubungan organisasi para anggotanya, sering dirumuskan bahwa hak organisasi diperolehnya melalui penuaian kewajiban oleh para anggotanya dan sebaliknya hak para anggota organisasi merupakan kewajiban organisasi untuk memenuhi. Pandangan ini biasanya mengejawantahkan pada tuntutan adanya kepemimpinan yang demokratik dalam organisasi yang bersangkutan

$$
\text { Seorang pemimpin yang }
$$
efektif adalah pimpinan yang mampu menunjukkan jalan yang dapat ditempuh oleh para bawahannya sehingga gerak maju dari posisi sekarang ke posisi yang diinginkan di masa yang akan datang dapat berlangsung dengan mulus. Salah satu mekanisme yang dipandang efektif untuk mewujudkan keadaan seperti diatas adalah dengan memperhitungkan dua hal, yaitu : pertama, kejelasan tugas yang harus dilakukan dan kedua, perhatian pimpinan kepada 
kepentingan dan kebutuhan para bawahannya

Motivasi dan gaya kepemimpinan seorang manajer akan mempengaruhi produktivas kerja karyawan. Di bidang industri, produktivitas mempunyai arti ukuran yang relatif nilai atau ukuran yang ditampilkan oleh daya produksi, yaitu sebagai campuran dari produksi dan aktivitas; sebagai ukuran, yaitu seberapa baik kita menggunakan sumber daya dalam mencapai hasil yang diinginkan.

Sumber daya manusia merupakan elemen yang paling strategis dalam organisasi, harus diakui dan diterima manajemen. Peningkatan produktivitas kerja hanya mungkin dilakukan oleh manusia. Sebaliknya, sumber daya manusia pula yang dapat menjadi penyebab terjadinya pemborosan dan inefisiensi dalam berbagai bentuk (Siagian 2002), Karena itu memberikan perhatian kepada unsur manusia merupakan salah satu tuntutan dalam keseluruhan upaya peningkatan produktivitas kerja

Bagi karyawan bekerja dalam sebuah perusahaan atau organisasi dengan memperoleh imbalan biasanya didasarkan atas keyakinan bahwa dengan bekerja pada perusahaan itu seseorang akan dapat memuaskan berbagai kebutuhannya, tidak hanya dibidang material, seperti sandang, pangan, papan dan kebutuhan kebendaan lainya, akan tetapi juga diberbagai kebutuhan lainnya yang bersifat sosial, prestise, kebutuhan psikologis dan intelektual (Siagian 2002)

\begin{tabular}{lrr}
\multicolumn{1}{c}{ Kepuasan } & kerja & akan \\
mempengaruhi & peran & dan \\
produktivitas & kerja & karyawan.,
\end{tabular}

terlepas dari apakah pekerjaan itu sarat teknologi atau tidak, namun pada akhirnya manusialah yang akan menjadikan pekerjaan itu efektif atau tidak, produktif atau tidak.

Rendahnya produktivitas kerja dari karyawan dalam suatu organisasi atau perusahaan merupakan gejala atau masalah yang dapat menyebabkan perusahaan tersebut kurang stabil, karena dapat menimbulkan ketidakmaksilan pencapaian tujuan perushaan, karena itu pemberian motivasi sekaligus penerapan gaya kepemimpinan menjadi dasar dan teori dalam mengelola karyawan agar tetap berjalan sesuai dengan roda dan tujuan organisasi (Nawawi 2003).

Pada dasarnya, setiap manusaia mau bekerja dikarenakan untuk dapat memenuhi kebutuhan dan keinginannya (fisik dan mental), baik itu kebutuhan yang disadari maupun kebutuhan yang tidak disadari. Dasar dari motivasi kerja seorang karyawan yaitu untuk memenuhi kebutuhannya. Jika dalam proses pemenuhan kebutuhan tersebut karyawan merasakan adanya peluang dalam mencapai tujuan untuk memenuhi kebutuhannya, maka motivasi untuk lebih giat dan semangat bekerja akan makin bertambah. Saat tujuannya tercapai, seseorang karyawan akan merasakan kepuasan dari aktivitasnya yang dikerjakan dalam pemenuhan kebutuhan tersebut. Masalah yang timbul yaitu bahwa masing-masing orang memiliki kebutuhan yang berbeda antara satu sama yang lain. Maka perusahaan haruslah menjadi suatu lembaga yang menyediakan 
kesempatan dalam pemenuhan kebutuhan bagi para pekerjanya.

Lebih lanjut, studi empirik menunjukan bahwa orang yang mempunyai motivasi yang kuat terdorong untuk menjadi dinamis, kreatif, inovatif, serta terbuka namun tetap kritis dan tanggap terhadap ide-ide baru dan perubahan-perubahan. Jika sikap positif dari motivasi ini diarahkan melalui model gaya kepemimpinan yang dapat memperbesar kinerja karyawan tersebut maka dapatlah tercipta tingkat produktivitas yang lebih optimum. Dalam kaitannya dengan tenaga kerja, maka produktivitas kerja karyawan merupakan perbandingan antara hasil yang dicapai dengan peran serta tenaga kerja per satuan waktu.

Tujuan penelitian ini dilakukan untuk mengetahui apakah motivasi kerja dan gaya kepemimpinan mempunyai pengaruh terhadap produktivitas kerja karyawan dalam suatu perusahaan. Penelitian ini diharapkan dapat memberikan manfaat bagi perusahaan dalam memberikan motivasi kerja dan lingkungan yang baik dari perusahaan kepada karyawan sehingga tujuan perusahaan dapat tercapai dengan adanya sumber daya manusia yang berkualitas. Selain itu, dapat menjadi salah satu pertimbangan bagi manajer dalam menciptakan sebuah strategi untuk memotivasi karyawannya dan meningkatkan suasana kerja yang lebih baik dan menciptakan suasana atau lingkungan kerja yang lebih mendukung.

\section{METODE PENELITIAN}

Penelitian yang di lakukan merupakan penelitian kuantitatif. Penelitian kuantitatif adalah penelitian yang diperoleh dengan mengukur nilai satu atau lebih variable dalam sample. Penelitian kuantitatif mengunakan metode untuk menguji teori-teori tertentu dengan meneliti hubungan antar variabel. Dengan tujuan untuk mengetahui pengaruh motivasi, gaya kepemimpinan terhadap produktivitas kerja karyawan (Sugiyono 2012).

Dalam peneltian ini populasi yang di ambil adalah karyawan yang bekerja pada PT Cahaya Berlian dengan jumlah sampel 100 responden. Pengambilan sampel dilakukan dengan teknik pengambilan sample accidental sampling yaitu mengambil responden sebagai sampel berdasarkan kebetulan, dimana siapa saja yang secara kebetulan bertemu dengan peneliti dapat digunakan sebagai sampel bila orang yang kebetulan ditemui cocok dengan kriteria yang akan dijadikan sampel.

Pengumpulan data yang
dilakukan melalui metode
kuesioner, metode wawancara studi
pustaka. Skala pengukuran dan
metode pengukuran yang di
gunakan pada penelitian ini adalah
skala Likert.




\section{Tabel 1 Operasional Variabel}

\begin{tabular}{|c|c|c|c|}
\hline variabel & Definisi operasional & Indikator & Skala \\
\hline Motivasi & $\begin{array}{l}\text { dorongan adalah suatu } \\
\text { dorongan yang menjadi } \\
\text { pangkal seseorang } \\
\text { melakukan sesuatu atau } \\
\text { bekerja ( Luthans 2005) }\end{array}$ & $\begin{array}{l}\text { - Upah } \\
\text { - Lingkunga } \\
\text { n Kerja } \\
\text { - Insentif } \\
\text { - Promosi } \\
\text { - Prestasi }\end{array}$ & Likert \\
\hline $\begin{array}{l}\text { Gaya } \\
\text { kepemimpinan }\end{array}$ & $\begin{array}{l}\text { perilaku dan strategi, } \\
\text { sebagai hasil kombinasi } \\
\text { dari falsafah, } \\
\text { ketrampilan,sifat,sikap,ya } \\
\text { ng sering diterapkan oleh } \\
\text { seorang pemimpin ketika } \\
\text { ia mencoba } \\
\text { mempengaruhi kinerja } \\
\text { bawahannya } \\
\text { (Tampubolon,2007) }\end{array}$ & $\begin{array}{l}\text { - Humanis } \\
\text { - Efisien } \\
\text { - Keteladana } \\
\text { n } \\
\text { - Motivator } \\
\text { - Pengayom }\end{array}$ & Likert \\
\hline $\begin{array}{l}\text { Produktivitas } \\
\text { kerja }\end{array}$ & $\begin{array}{lr}\text { Produktivitas } & \text { adalah } \\
\text { ukuran } & \text { terakhir } \\
\text { keberhasilan } & \text { seorang } \\
\text { karyawan } & \text { dalam } \\
\text { melaksanakan } & \\
\text { pekerjaannya } & \end{array}$ & $\begin{array}{l}\text { - Kualiti } \\
\text { - Kuantiti } \\
\text { - Tepat } \\
\text { waktu } \\
\text { - Efisien } \\
\text { - Tim Work }\end{array}$ & Likert \\
\hline
\end{tabular}

\section{Teknik Analisis Data}

Pada tahapan ini data diolah sedemikian rupa sehingga berhasil disimpulkan kebenaran-kebenaran yang dapat di pakai untuk menjawab persoalan yang di ajukan dalam penelitian. Analisa data bias dibedakan menjadi dua yaitu analisa kualitatif dan analisa kuantitatif. Apabila data yang dikumpulkan hanya sedikit atau berwujud kasus-kasus maka analisa yang di pakai kualitatif sedangkan apabila data yang di kumpul berjumlah besar dan mudah diklasifikasikan kedalam analisa kuantitatif. Kategori-kategori, maka analisis yang di pakai adalah kuantitatif

Data adalah semua keterangan seseorang yang di jadikan responden maupun yang berasal dari dokumen-dokumen baik dalam bentuk statistik atau dalam bentuk lainya guna keperluan penelitian. Tujuan metode analisis data adalah untuk menjawab rumus masalah dan pengujian hipotesis yang di ajukan, menginterprestasikan dan menarik kesimpulan dari sejumlah data yang terkumpul.

\section{Uji Instrumen}

Uji Validitas

Uji validitas digunakan untuk mengetahui apakah item-item yang diajukan dalam kuesioner dapat digunakan untuk mengukur keadaan responden sebenarnya dan menyempurnakan kuesioner tersebut (Wibowo 2012). Perhitungan ini akan dilakukan dengan bantuan komputer program SPSS (Statistical Package for Social Science). Untuk menentukan nomor-nomor item yang valid dan yang gugur, perlu dikonsultasikan dengan tabel $r$ product moment. Kriteria penilaian uji validitas, adalah:

a. Apabila $\mathrm{r}$ hitung $>\mathrm{r}$ tabel (pada taraf signifikansi 5\%), maka dapat dikatakan item kuesioner tersebut valid.

b. Apabila $r$ hitung $<\mathrm{r}$ tabel (pada taraf signifikansi 5\%), maka dapat dikatakan item kuesioner tersebut tidak valid.

Menurut Wibowo (2012), ada dua syarat penting yang berlaku pada sebuah angket, yaitu keharusan sebuah angket untuk valid dan reliabel. Suatu angket dikatakan valid jika pertanyaan pada suatu angket mampu untuk mengungkapkan sesuatu yang diukur oleh angket tersebut. Sedangkan suatu angket dikatakan reliabel jika jawaban seseorang terhadap pertanyaan konsisten dari waktu ke waktu. Di mana validitas data diukur dengan membandingkan $\mathrm{r}$ hasil dengan $\mathrm{r}$ tabel ( $r$ product moment), jika :

a. $\mathrm{r}$ hasil $>\mathrm{r}$ tabel, data valid 
b. $\mathrm{r}$ hasil $<\mathrm{r}$ tabel, data tidak valid

\section{Uji Reliabilitas}

Reliabilitas adalah istilah yang di pakai untuk menunjukan sajauh mana suatu pengukuran relative konsisten apabila pengukuran diulangi dua kali atau lebih. Uji ini menunjukan sejauh mana alat pengukuran dapat menunjukan dapat di percaya atau tidak dalam mengukur sampel (Wibowo 2012). Menurut Sunyoto (2011) pengertian reliabilitasi adalah suatu alat yang di gunakan untuk mengukur suatu kuesioner yang merupakan indikator dari variabel atau konstruktur.

Pengujian reliabilitas

terhadap seluruh item atau pertanyaan pada penelitian ini akan menggunakan rumus koefisien Cronbach Alpha. Nilai Cronbach Alpha pada penelitian ini akan digunakan nilai 0.6 dengan asumsi bahwa daftar pertanyaan yang diuji akan dikatakan reliabel bila nilai Cronbach Alpha $\geq 0.6$.

Syarat suatu alat ukur menunjukkan kehandalan yang semakin tinggi adalah apabila koefisien reliabilitas (alpha cronbach) yang mendekati angka satu. Apabila koefisien (alpha cronbach) lebih besar dari 0.6 maka alat ukur dianggap handal atau terdapat internal consistency reliability dan sebaliknya bila alpha cronbach lebih kecil dari 0.3 maka dianggap kurang handal atau tidak terdapat internal consistency reliability

\section{Uji Hipotesis}

Uji Hipotesis bertujuan untuk mengetahui signifikan atau tidaknya pengaruh variabel independen terhadap variabel dependen. Untuk lebih jelas berikut dibahas setiap pengujian hipotesis yang digunakan dalam penelitian ini:

a. Koefisien Determinasi $\left(\mathbf{R}^{2}\right)$

Koefisien determinasi $\left(\mathrm{R}^{2}\right) \mathrm{di}$ gunakan untuk mengukur seberapa jauh kemampuan model dalam menerangkan variasi variabel dependen. Nilai koefisien determinasi adalah antara 0 dan 1 . Nilai $\mathrm{R}^{2}$ yang kecil bararti variabel dependen sangat terbatas, Ghozali (2005).

$\begin{array}{llr}\text { b. Uji Parsial (t) } & \\ \text { Uji t } & \text { digunakan } & \text { untuk } \\ \text { mengetahui } & \text { apakah } & \text { variabel } \\ \text { independen } & \text { secaara } & \text { parsial } \\ \text { berpengaruh } & \text { secara } & \text { signifikan }\end{array}$
terhadap variabel dependen dengan menggunakantingkat keyakinan 95\% $(\alpha=0.05)$. Uji ini dilakukan sekaligus untuk melihat koefisien regresi secara individual variabel penelitian, Ghozali (2005).

\section{c. Uji Simultan (F)}

Uji ini digunakan untuk menegtahui apakah variabel independen $(\mathrm{x})$, berpengaruh secara signifikan terhadap variabel dependen (Y). $F_{\text {hitung dapat dicari }}$ dengan rumus sebagai berikut:

Tahap-tahap yangdilakukan untuk menguji dari uji $\mathrm{F}$ adalah sebagai berikut:

a. Merumuskan hipotesis

Ho : tidak ada pengaruh secara signifikan dan positif antara $\mathrm{X}$ terhadap Y

$\mathrm{Ha}$ : ada pengaruh secara signifikan dan positif antara $\mathrm{X}$ terhadap Y

b. Menentukan tingkat signifikan Tingkat signifikan menggunakan $\mathrm{a}=5 \%$ Ho diterima jika $0,05<\mathrm{sig}$ Ho ditolak jika 0,05> sig

c. Menentukan nilai $F_{\text {hitung }}$ 
Berdasarkan hasil $F_{\text {hitung }}$ dari SPSS

d. Menentukan $\mathrm{F}_{\text {tabel }}$

Berdasarkan hasil $F_{\text {tabel }}$ dari SPSS

d. Kriteria pengujian

- Ho diterima jika $F_{\text {hitung }}<F_{\text {tabel }}$

- Ha ditolak jika $F_{\text {hitung }}>F_{\text {tabel }}$

e. Membandingkan $F_{\text {hitung }}$ dengan $F_{\text {tabel }}$

f. Kesimpulan

\section{HASIL DAN PEMBAHASAN \\ Profil responden}

Tabel 2 Deskripsi Responden

Berdasarkan Pendidikan

\begin{tabular}{|c|c|c|}
\hline Pendidikan & Frequency & Percent \\
\hline SMA & 16 & 14.7 \\
\hline DIPLOMA & 58 & 53.2 \\
\hline Sarjana & 35 & 32.1 \\
\hline Total & 109 & 100.0 \\
\hline
\end{tabular}

Identitas Responden Menurut

Pendidikan di mana dari 109

responden, 16 responden (14.7\%)

berpendidikan SMA, 58 responden (53.2\%) berpendidikan diploma, dan 35 responden $(32.1 \%)$ berpendidikan sarjana.

\section{Tabel 3 Deskripsi Responden}

\section{Berdasarkan Masa Kerja}

\begin{tabular}{|c|c|c|}
\hline Masa kerja & Frequency & Percent \\
\hline 1 sampai dengan 3 tahun & 10 & 9.2 \\
\hline $\begin{array}{l}3 \text { sampai dengan kurang } \\
\text { dari } 5 \text { tahun }\end{array}$ & 97 & 89.0 \\
\hline lebih dari 5 tahun & 2 & 1.8 \\
\hline Total & 109 & 100.0 \\
\hline Tabel & menur & ukkan \\
\hline
\end{tabular}

Identitas Responden Menurut Masa Kerja terdapat 10 responden $(9.2 \%)$ telah bekerja selama 1 sampai dengan 3 tahun, 97 responden (89\%) telah bekerja selama 3 sampai 5 tahun, dan 2 responden $(1.8 \%)$ telah bekerja selama lebih dari 5 tahun.

\section{Uji Validitas dan Reliabilitas \\ Tabel 4. Hasil uji validitas dan reliabilitas

\begin{tabular}{|c|c|c|c|}
\hline variabel & item & validitas & reliabilitas \\
\hline \multirow{6}{*}{$\mathrm{X} 1$} & 1 & 0,927 & \multirow{6}{*}{0.913} \\
\hline & 2 & 0,971 & \\
\hline & 3 & 0,891 & \\
\hline & 4 & 0,735 & \\
\hline & 5 & 0,801 & \\
\hline & 6 & 0,795 & \\
\hline \multirow{6}{*}{$\mathrm{X} 2$} & 1 & 0,921 & \multirow{6}{*}{0.947} \\
\hline & 2 & 0,910 & \\
\hline & 3 & 0,777 & \\
\hline & 4 & 0,925 & \\
\hline & 5 & 0,915 & \\
\hline & 6 & 0,92 & \\
\hline \multirow{6}{*}{$\mathrm{Y}$} & 1 & 0,705 & \multirow{6}{*}{0.939} \\
\hline & 2 & 0,926 & \\
\hline & 3 & 0,907 & \\
\hline & 4 & 0,921 & \\
\hline & 5 & 0,886 & \\
\hline & 6 & 0,905 & \\
\hline & asil & uji & eliabilitas \\
\hline
\end{tabular} \\ menunjukkan nilai $\mathrm{r}$ hitung $>0.3$ yang artinya seluruh item pertanyaan pada setiap variable adalah valid, begitupula reliabilitas yang menunjukkan nilai cronbah alpha > 0.6 yang berarti seluruh variable teruji kehandalannya atau reliable untuk dilakukan pengujian berikutnya.}

\section{Uji Hipotesis}

Hasil uji hipotesis dapat disimpulkan dari tabel dibawah ini :

Tabel 5 Hasil Uji T

\begin{tabular}{lccc}
\hline \multicolumn{1}{c}{ Variabel } & Koef & T & Sig. \\
\hline Motivasi & 0.453 & 5.100 & .000 \\
\hline $\begin{array}{l}\text { Gaya } \\
\text { kepemimpinan }\end{array}$ & 0.504 & 5.981 & .000 \\
\hline
\end{tabular}

Berdasarkan hasil pengujian diatas dapat dilihat variable motivasi (X1) dengan nilai koefisien sebesar 0.453 berpengaruh secara positif terhadap produktivitas kerja dan signifikan hal ini terlihat dari nilai signifikan $0.000<0.05$ dan 
nilai t hitung $5.100>\mathrm{t}$ tabel 1.982 . Hal ini memperkuat penelitian yang dilakukan oleh peneliti sebelumnya, bahwa motivasi berpengaruh terhadap produktivitas karyawan.

Begitupula hasil pengujian diatas dapat dilihat variabel gaya kepemimpinan (X2) dengan nilai koefisien sebesar 0.504 berpengaruh secara positif terhadap produktivitas kerja, dan signifikan, hal ini terlihat dari nilai signifikan $0.000<0.05$ dan nilai $\mathrm{t}$ hitung 5.981> t tabel 1.982.Penelitian ini juga menhasilkan keputusan yang sama dengan penelitian terdahulu, bahwa gaya kepemimpinan memiliki pengaruh terhadap produktivitas kerja karyawan.

Tabel 6 Uji F

\begin{tabular}{lll}
\hline Variabel & F & Sig. \\
\hline Produktivitas & 310.038 & .000 \\
\hline
\end{tabular}

Berdasarkan hasil pengujian pada pada uji $\mathrm{F}$ dapat dilihat bahwa secara bersama sama variabel motivasi dan gaya kepemimpinan berpengaruh signifikan terhadap produktivitas kerja, hal ini dibuktikan dengan nilai signifikansi sebesar $0.000<0.05$ dan nilai $F$ hitung $310.038>3.082$.

\section{PENUTUP}

\section{Kesimpulan}

Berdasarkan hasil penelitian dapat disimpulkan beberapa poin berikut :

1. Peningkatan motivasi kerja yang baik dalam perusahaan dapat mendukung kepada produktivitas kerja yang baik pula, ini menunjukkan otivasi berpengaruh secara positif dan signifikan terhadap produktivitas kerja karyawan PT. Cahaya Berlian.
2. Gaya kepemimpinan menunjukkan pengaruh yang positif dan signifikan terhadap produktivitas kerja karyawan. Dengan memiliki sifat dan gaya kepemimpinan yang baik dan diharapkan oleh karyawan maka hasil kerja karyawan juga akan sesuai dengan tujuan perusahaan dan meningkatkan produktivitas.

\section{Saran}

Adapun saran yang diberikan kepada praktisi yaitu manajemen PT Cahaya Berlian adalah dengan memaksimalkan pemberian motivasi kepada karyawan dan juga membangun sebuah gaya kepemimpinan yang bagus agar tercapai produktivitas kerja dan tujuan perusahaan. Selanjutnya bagi peneliti selanjutnya agar mengembangakan penelitian dalam bidang manajemen sumber daya manusia terutama produktivitas kerja.

\section{DAFTAR PUSTAKA}

Ghozali, Imam. 2005. Aplikasi Analisis Multivariate dengan SPSS. Semarang: Badan Penerbit UNDIP.

Hasibuan \& Arifin. 2005. Teori dan Pengembangan Manajemen. Andi Yogyakarta

Nawawi., H. 2005. Manajemen Stratejik. Gadjah Mada Pers : Yogyakarta

Sari. 2004. Pengaruh Kompensasi dan Gaya Kepemimpinan terhadap Produktivitas Kerja Karyawan, Yogyakarta.

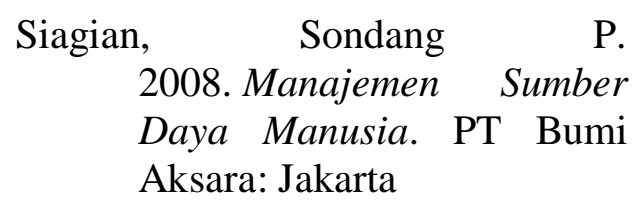


Santoso, Singgih, 2005. Statistik Multivariat, Andi Yogyakarta

Sugiyono. 2012 ,A, 2004 . Metodologi Penelitian. Rineka Cipta Bandung

Parasuraman. 2005, Customer Orientation as a Mediator of Organizational Culture's In fluence on Buyer-Seller Relationships. Journal of Personal Selling \& Sales Management. 16(4): 33-52

Sunyoto, Suyanto 2011. Analisis regresi untuk uji hipotesis, Yogyakarta. Caps

Wibowo, Agung Edy, 2013. SPSS dalam Perspektif dan Riset Bisnis, Gava Media Yogyakarta 